\title{
Использование микроэмульсий для извлечения и одновременного концентрирования бенз(а)пирена из почвы
}

\author{
Толмачева Н.Г., Чжан М., Пирогов А.В., Шпигун О.А. \\ Московский государственный университет имени М.В. Ломоносова, Москва
}

Поступила в редакцию 25.11.2016 г.

\begin{abstract}
Микроэмульсии (МЭ) различного состава использованы в качестве экстрагентов бенз(а)пирена (БаП) из почвы с последующим расслоением МЭ, одновременным концентрированием БаП в органической фазе и его определением методом высокоэффективной жидкостной хроматографии (ВЭЖХ). Расслоение МЭ осуществляется добавлением избытка хлорида кальция и осаждением малорастворимой соли додецилсульфата кальция. Определены коэффициенты концентрирования БаП в органической фазе, образующейся после расслаивания МЭ. Обсуждены достоинства предложенного подхода по сравнению с существующими аттестованными методиками определения БаП.
\end{abstract}

Ключевые слова: микроэмульсии, бенз(а)пирен, высокоэффективная жидкостная хроматография, концентрирование.

\section{The use of microemulsions for the extraction and simultaneous pre-concentration of benz(a)pyrene in soil}

\author{
Tolmacheva N.G., Jhan M., Pirogov A.V., Shpigun O.A. \\ M.V. Lomonosov Moscow State University, Moscow
}

Microemulsions of different composition were used for the extraction of benz(a)pyrene (BaP) from several types of soils with subsequent decay of the microemulsions, simultaneous pre-concentration of $\mathrm{BaP}$ in organic layer and following HPLC determination. Decomposition of ME was performed by addition of calcium chloride and precipitation of poorly soluble calcium dodecylsulfate. ME have high ability to dissolve both hydrophylic and hydrophobic substances at the same time. At destruction of ME on two phases - organic, so-called "oil", and water are formed. Hydrophobic compounds are going to the oil phase and can be concentrated due to decrease of total amount of solvent. Such approach allows to lower significantly limits of the detection and to reduce errors of the determination. Sample pretreatment takes about 15 minutes that by 3-4 times faster than in the existing techniques. Dependences of extent of concentrating of $\mathrm{BaP}$ in an organic layer after decomposition of ME $v s$ structure of $\mathrm{ME}$ are studied (nature and concentration of $c o$-surfactant, the nature of oil and conditions of decomposition - temperature and time). It was found that using of ME with of $3 \%$ of SDS, $0.8 \%$ benzene and $6 \% i$-pentanol results in the greatest extent of concentration of $\mathrm{BaP}$ in an organic phase after decomposition of ME. The ME was used through the work. It is shown that at time of extraction of 10 minutes and addition of $40 \mathrm{ml}$ of ME to $2 \mathrm{~g}$ of the soil the extent of extraction reaches the maximal value.(in range of $92-102 \%$ and slightly depends on type of soils). The limit of the detection of BaP was 0.1 microgram $/ \mathrm{kg}$ of soil.

Keywords: benz(a)pyren, microemulsion, high performance liquid chromatography. 


\section{Введение}

Полициклические ароматические углеводороды (ПАУ) относят к токсикантам I степени опасности [1]. Из-за своей высокой токсичности, канцерогенности и мутагенности Агентствами по охране окружающей среды (ЕРА) США и стран Европейского Союза (ЕС) 16 полициклических ароматических углеводородов (нафталин, аценафтен, флуорен, аценафтилен, фенантрен, антрацен, флуорантен, пирен, хризен, бенз $(a)$ антрацен, бенз $(b)$ флуорантен, бенз $(k)$ флуорантен, бенз $(a)$ пирен, дибенз $(a, h)$ антрацен, индено $(1,2,3-c d)$ пирен, бенз $(g, h, i)$ перилен) были внесены в список наиболее опасных загрязнителей воды, воздуха и почвы [2]. В России установлены нормативы для бенз(а)пирена во всех средах [3-6].

Существует множество аттестованных методик определения ПАУ, в частности бенз (a)пирена, в объектах окружающей среды, биологических и пищевых объектах, основанных на спектральных [7, 8], электрохимических [9] и хроматографических [10] методах. Проблемой определения БаП в различных объектах со сложной матрицей является длительный и трудоемкий процесс пробоподготовки. Обычно используют жидкостную или твердофазную экстракцию с дальнейшим упариванием растворителя и перерастворением пробы. Такие подходы включают несколько длительных стадий, на каждой из которых увеличивается погрешность определения ПАУ.

Целью работы являлось использование микроэмульсий (МЭ) типа «масло в воде» [11-15] в качестве экстрагентов БаП из различных типов почв с последующим расслоением МЭ и концентрированием в органической фазе. Такой подход позволяет существенно сократить время пробоподготовки, снизить пределы обнаружения и уменьшить погрешность определения на стадии пробоподготовки.

\section{Эксперимент}

Приборы и материалы. В ходе работы использовали следующие реактивы: бенз(а)пирен (Эколан, Россия), додецилсульфат натрия (Pancreac, Испания), $\boldsymbol{H}_{\text {- }}$ бутанол, изо-пентанол (Carl Roth, Германия), ацетонитрил (Panreac, Испания), хлорид кальция (MERCK, Германия).

Степень извлечения ПАУ и их коэффициенты концентрирования в органической фазе определяли с помощью жидкостного хроматографа Agilent 1200, оснащенного четырехканальным градиентным насосом, он-лайн дегазатором подвижной фазы, термостатом колонок, диодно-матричным и флуориметрическим детекторами (Agilent Technologies, США). Для сбора и обработки данных использовали программно-аппаратный комплекс Chemstation версии B.02.01-SR2(260). Для отбора аликвот использовали автоматические дозаторы с диапазонами установки отбираемого объема в интервалах 5-50 мкл, 20-200 мкл, 100-1000 мкл, 1000-5000 мкл соответственно (предел допустимой относительной погрешности измерения не более $\pm 5 \%$, LABMATE, Польша). Взвешивание точных навесок проводили на весах ExplorerPro (OhausCorporation, США), точность которых составляла 0,0001 г. Для центрифугирования образцов использовали центрифугу CM-50 (Elmi, Латвия). Для проведения ультразвуковой жидкостной экстракции применяли ультразвуковую ванну УЗВ (ПКФ Сапфир, Россия).

Приготовление микроэмульсий. В работе использовали МЭ типа «масло» в воде следующего состав: 3\% додецилсульфата натрия (ДДСН), 0.8\% масла, 6\% coПАВ, 90.2\% воды. Навеску ДДСН растворяли в точно измеренном количестве воды в ультразвуковой ванне, затем вводили необходимое количество органических рас- 
творителей и снова перемешивали в ультразвуковой ванне до образования микроэмульсии ( 5 минут).

Условия ВЭЖХ анализа. В ходе работы использовали колонку Luna C18 (2) $(150 \times 4.6$ мм, размер частиц - 5 мкм) (Phenomenex, США). Объем вводимой пробы 20 мкл. Рабочая температура колонки $30^{\circ} \mathrm{C}$. Скорость подачи элюента $1 \mathrm{~cm}^{3} /$ мин. Подвижная фаза - ацетонитрил: вода, градиентное элюирование. Осуществляли флуориметрическое детектирование при $\lambda$ возб. $=365$ нм, $\lambda$ эм. $=412 \mathrm{Hм}$.

Пробоподготовка почвы. Для извлечения БаП из почв навеску воздушносухой почвы (2 г) помещали в коническую плоскодонную колбу на $100 \mathrm{~cm}^{3}$. Добавляли $30 \mathrm{~cm}^{3}$ МЭ, после чего колбу помещали в ультразвуковую баню на 10 минут. Отбирали $1 \mathrm{~cm}^{3}$ экстракта и центрифугировали при 16000 оборот/минуту в течение 3 минут. Затем отбирали надосадочную жидкость для дальнейшего хроматографического анализа.

Для расслаивания МЭ после экстракции в ультразвуковой бане к смеси добавляли избыток (по отношению к ДДСН) сухого хлорида кальция и помещали в ультразвуковую баню на 5 минут для осаждения ДДСН и расслоения микроэмульсии. После чего отбирали «масляную» фазу и центрифугировали при 16000 оборот/минуту в течение 3 минут. Затем отбирали надосадочную жидкость для дальнейшего хроматографического анализа.

\section{Обсуждение результатов}

Микроэмульсии обладают высокой солюбилизирующей способностью и могут одновременно растворять гидрофильные и гидрофобные соединения. При разрушении МЭ образуются две фазы - органическая, т.н. «масло», и водная. Гидрофобные соединения будут находиться в масляной фазе после расслоения МЭ и концентрироваться за счет уменьшения общего объема растворителя (рис. 1).

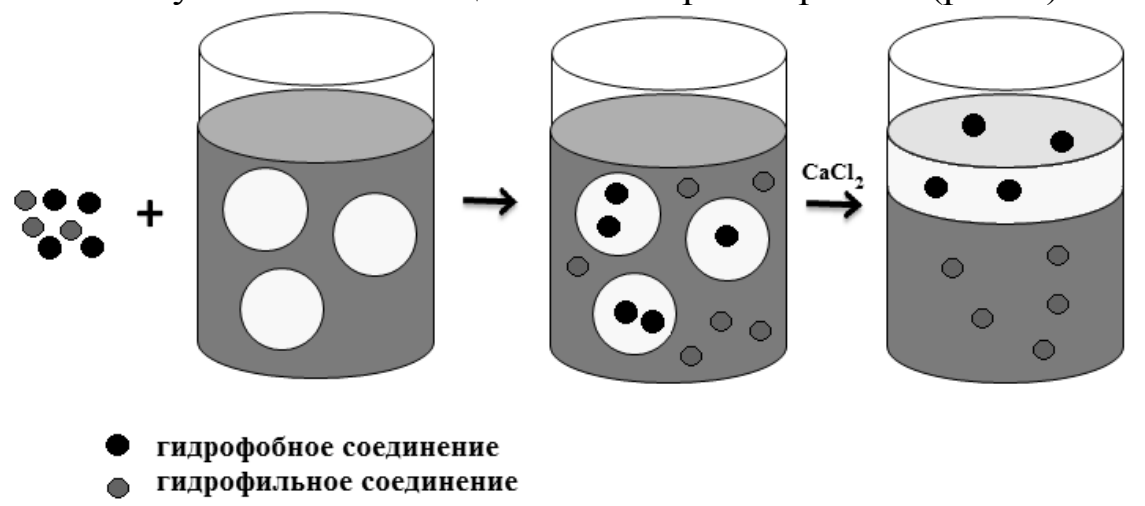

Рис. 1. Схема использования МЭ как экстрагентов с последующим расслоением МЭ и концентрированием целевых компонентов в одной из образовавшихся

Такой подход был впервые нами использован для извлечения и последующего хроматографического определения БаП из трех типов почв. Пробоподготовка с использованием МЭ включает несколько простых шагов: приготовление МЭ, экстракция аналитов, расслаивание микроэмульсии, отбор органической фазы и центрифугирование. Весь процесс пробоподготовки занимает около 15 минут, что в 3-4 раза экспресснее, чем в существующих методиках [16] и [17].

Изучены зависимости степени концентрирования бенз(a)пирена в органическом слое после расслаивания МЭ от состава МЭ (от природы и концентрации соПАВ, природы масла и условий расслаивания - температура и время (рис 2а-г). При использовании МЭ состава 3\% ДДСН, 0.8\% бензол и 6\% изо-пентанола достигается 
наибольшая степень концентрирования БаП в органической фазе после расслаивания МЭ, поэтому в дальнейшей работе использовали МЭ такого состава. Показано, что при времени экстракции 10 минут и объеме МЭ, как экстрагента, 30 мл на 2 г почвы степень извлечения достигает максимального значения. В этих условиях проводили экстракцию БаП из почв.
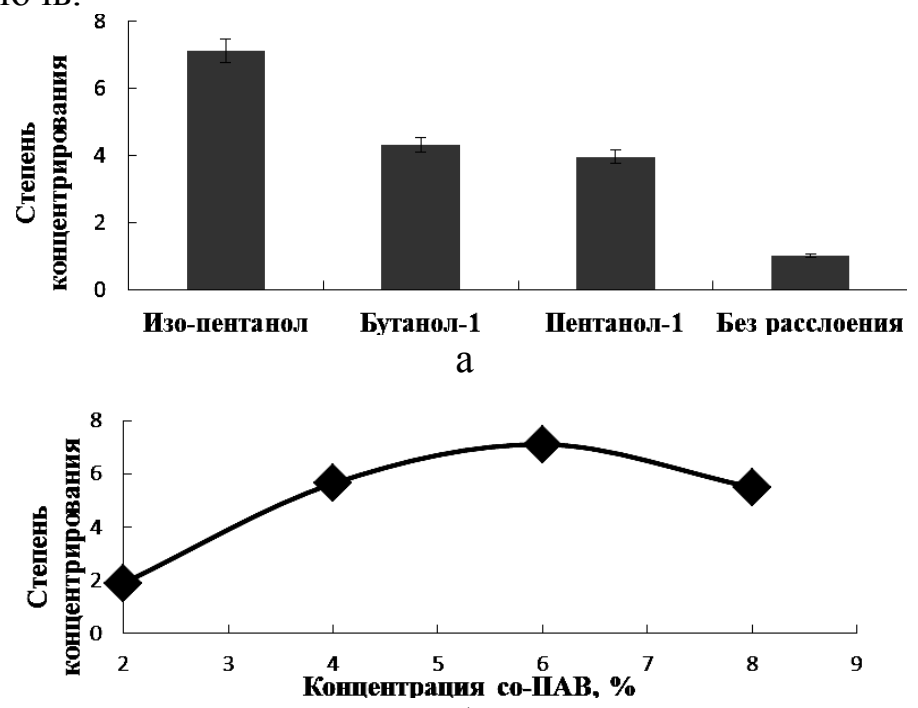

6

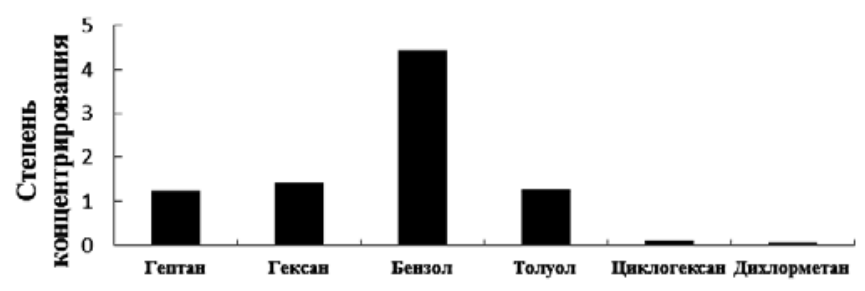

B

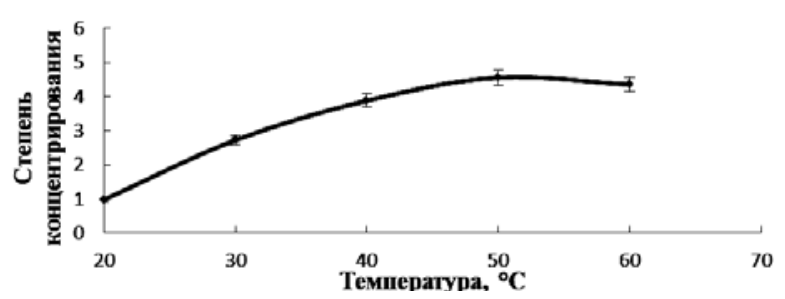

$\Gamma$

Рис. 2. Степень концентрирования БаП в зависимости от: (а) типа со-ПАВ, (б) концентрации изо-пентанола, (в) типа масла, (г) температуры экстракции. Концентрация ДДСН в микроэмульсии 3\%. Время экстракции 10 минут

Таблица 1. Степень извлечения БаП из различных типов почв: песка, глины и верхового торфа, с использованием МЭ $(n=3, P=0.95)$

\begin{tabular}{|c|c|c|c|c|}
\hline \multirow{2}{*}{ Соединение } & Введено (до- & \multicolumn{3}{|c|}{ Степень извлечения, \% } \\
\cline { 3 - 5 } & бавка), мкг/кг & Песок & Глина & Верховой торф \\
\hline \multirow{2}{*}{ Бенз $(a)$ пирен } & 100.0 & $102.2 \pm 5.1$ & $92.7 \pm 4.6$ & $94.0 \pm 4.7$ \\
& 20.0 & $91.8 \pm 4.6$ & $99.5 \pm 5.0$ & $91.8 \pm 4.6$ \\
\hline
\end{tabular}

Для извлечения БаП выбрано три типа почв: песок, глина и верховой торф. Методом «введено-найдено» определили степень извлечения БаП из этих почв с добавками 100 мкг/кг и 20 мкг/кг каждого ПАУ с использованием МЭ в качестве экстрагента. Результаты для песка, глины и верхового торфа представлены в табл. 1. При 
получении результатов было учтено содержание БаП в «холостой» пробе (найден только в торфе). Найдено, что степень извлечения БаП находится в диапазоне 92$102 \%$ и слабо зависит от типа почв.

При добавлении десятикратного избытка сухого хлорида кальция к МЭ на основе ДДСН начинается ее расслаивание и образование двух несмешивающихся фаз: водная и «масло». Из-за своей высокой гидрофобности БаП концентрируется в органической фазе после расслаивания. Коэффициент концентрирования БаП составляет около 6.

Предел обнаружения БаП и ПДК представлены в табл. 2. Полученные пределы обнаружения существенно ниже пределов допустимых концентраций (ПДК), установленных Агентствами по охране окружающей среды Канады и Голландии для некоторых ПАУ и ниже ПДК, установленного для бенз( $a)$ пирена в почве в России.

Таблица 2. Параметры градуировочных зависимостей, пределы обнаружения и ПДК для БаП в почвах.

\begin{tabular}{|c|c|c|c|c|c|c|}
\hline Соединение & \multicolumn{2}{|c|}{$\begin{array}{c}\text { Предел обнаружения, } \\
\mathrm{C}_{\text {мин }} \text { мкг/кг }\end{array}$} & \multicolumn{3}{c|}{ ПДК мкг/кг } \\
\hline & $\begin{array}{c}\text { Данная ра- } \\
\text { бота }\end{array}$ & {$[16]$} & {$[17]$} & $\begin{array}{c}\text { c/х почвы } \\
\text { (Канада) } \\
{[18]}\end{array}$ & $\begin{array}{c}\text { почвы (Гол- } \\
\text { ландия) [18] }\end{array}$ & $\begin{array}{c}\text { ГН } \\
2.7 .2041-06 \\
{[19]}\end{array}$ \\
\hline Бенз $($ a)пирен & 0.1 & 5 & 5 & 100 & 260 & 20 \\
\hline
\end{tabular}

Для оценки правильности предложенного подхода полученные результаты сравнивали с результатами аттестованных методик ПНД Ф 16.1:2.2:2.3:3.62-09 [16] и ПНД Ф 16.1:2:2.2:2.3:3.39-2003 (МУК 4.1.1274-03) [17]. В методике [16] аналиты экстрагировали диэтиловым эфиром на УЗ-ванне, затем концентрировали с помощью упаривания на песчаной бане до следовых количеств растворителя и перерастворяли в ацетонитриле. В методике [17] в качестве экстрагента использовали хлористый метилен, аналиты экстрагировали на УЗ-ванне, полученный экстракт декантировали через бумажный фильтр, концентрировали с помощью упаривания и перерастворяли в ацетонитриле. Результаты показали, что предложенный в настоящей работе подход обладает в несколько раз большей чувствительностью по сравнению с рассматриваемыми аттестованными методиками.

Прецизионность. Прецизионность методики оценивали путем определения сходимости результатов повторением анализа на 6 пробах одним химиком в один день на одном оборудовании и определения внутрилабораторной прецизионности при анализе в одной лаборатории одной и той же пробы с полным повторением процедуры приготовления пробы и выполнения измерений другим химиком.

Сходимость оценивали путем расчета относительного стандартного отклонения (RSD), полученного по последовательным определениям, выполненным одним химиком в один день. Оценку внутрилабораторной прецизионности при установленном доверительном интервале определяли по F-критерию Фишера и t-критерию Стьюдента. Результаты представлены в табл. 3. Показано, что методика обладает хорошей сходимостью (RSD менее 5\%) и внутрилабораторной прецизионностью, ввиду выполнения всех критериев приемлемости.

Таблица 3. Внутрилабораторная прецизионность определения бенз(а)пирена

\begin{tabular}{|c|c|c|}
\hline № опыта, показатель & Химик 1 & Химик 2 \\
\hline 1 & 2 & 3 \\
\hline 1 & 432.16 & 450.36 \\
\hline 2 & 426.24 & 434.26 \\
\hline
\end{tabular}

Tолмачева и др. / Сорбционные и хроматографические процессы. 2017. Т. 17. № 3 


\begin{tabular}{|c|c|c|}
\hline 1 & 2 & 3 \\
\hline 3 & 446.16 & 462.34 \\
\hline 4 & 431.26 & 438.64 \\
\hline 5 & 416.49 & 449.34 \\
\hline 6 & 427.64 & 474.46 \\
\hline Cреднее & 429.99 & 451.57 \\
\hline SD & 9.69 & 14.92 \\
\hline RSD, \% & 2.3 & 3.3 \\
\hline Табличный критерий Фишера $\mathrm{F}_{\text {таб̆л. }}(0.95,5,5)$ & \multicolumn{2}{|c|}{2.37} \\
\hline Расчетный критерий Стьюдента $\mathrm{t}_{\text {расч. }}$ & \multicolumn{2}{|c|}{1.21} \\
\hline Табличный критерий Стьюдента $\mathrm{t}_{\text {табл. }}(0.95,10)$ & \multicolumn{2}{|c|}{2.23} \\
\hline
\end{tabular}

Стабильность растворов. Стабильность анализируемых растворов при комнатной температуре изучали при $25^{\circ} \mathrm{C}$. Анализ пробы проводили сразу после приготовления, через 30 мин, через 60 мин и далее до тех пор, пока разница с первоначальным измерением составила более $5.0 \%$. Установлено, что раствор является стабильным в течение 48 часов.

Робастность. В ходе исследования робастности методики установлено, что варьирование параметров хроматографирования: состав подвижной фазы (ацетонитрила $\pm 5 \%)$, температура колонки $\left( \pm 10^{\circ} \mathrm{C}\right)$, скорость подвижной фазы $\left( \pm 0.2 \mathrm{~cm}^{3} /\right.$ мин $)$ не оказывает значимого влияния на количество найденного бенз(а)пирена в почве. Относительное отклонение не превышает 10.0\%. Уменьшению времени экстракции на 5 мин приводит к недостоверным результатам.

\section{Заключение}

Таким образом МЭ являются хорошими экстрагентами бенз(а)пирена из различных типов почв с последующим расслоением МЭ и концентрированием определяемыХ компонентов в органической фазе с последующим ВЭЖХ анализом. Предложенный подход характеризуется низкими пределами обнаружения, значительно упрощает процесс пробоподготовки, уменьшая общее время анализа, и уменьшает общее число стадий, что снижает погрешность определения.

Работа выполнена при финансовой поддержке гранта РНФ 16-13-10079. Aвторы работы выражают благодарность фирме Agilent Technologies за предоставленное оборудование.

\section{Список литературы}

1. Майстренко В.Н., Хамитов Р.3., Будников Г.К. Экологический мониторинг супертоксикантов. М. Химия. 1996. 319 с.

2. Алемасова А.С., Луговой К.С./ Экологическая аналитическая химия. Учебное пособие. Донецк. ДонНУ. 2010. 271 с.

3. ГН 2.1.5.1315-03. Предельно допустимые концентрации (ПДК) химических веществ в воде водных объектов хозяйственнопитьевого и культурно-бытового водопользования. Гигиенические нормативы. М. Фе- деральный центр гигиены и эпидемиологии Роспотребнадзора, 2003. 154 с.

4. СанПин 2.1.4.1074-01. Питьевая вода. Гигиенические требования к качеству воды централизованных систем питьевого водоснабжения. Контроль качества. Гигиенические требования к обеспечению безопасности систем горячего водоснабжения. Санитарно-эпидемиологические правила и нормативы. М. Федеральный центр гигиены и эпидемиологии Роспотребнадзора. 2002. 84 с. 
5. ГН 2.1.7.2041-06. Предельно допустимые концентрации (ПДК) химических веществ в почве. Гигиенические нормативы. М. Федеральный центр гигиены и эпидемиологии Роспотребнадзора. 2006. 15 с.

6. ГН 2.1.6.2309-07. Ориентировочные безопасные уровни воздействия (ОБУВ) загрязняющих веществ в атмосферном воздухе населенных мест .Гигиенические нормативы. М. Федеральный центр гигиены и эпидемиологии Роспотребнадзора. 2008. 105 с.

7. РД 52.04.186-89. Руководство по контролю загрязнения атмосферы. М. Госкомгидромет СССР, 1991. 695 с.

8. Аннотированный справочник методик выполнения измерений концентраций загрязняющих веществ в выбросах промышленных предприятий. С-Пб.:НИИ Атмосфеpa. $2006.93 \mathrm{c}$.

9. МР 146-1110. Измерение массовой концентрации бенз(а)пирена в питьевой воде вольтамперометрическим методом. М. Госкомсаэпиднадзор. 1997.

10. Williamson K.S., Petty J.D., Huckins J.N., Lebo J.A. et al. // Chemosphere. 2002. Vol. 49. pp. 703.

11.Пирогов А.В., Пашкова Е.Б., Попик М.В., Шпигун О.А. // Разработка и регистрация лекарственных средств. 2013. Т. 5. № 4. C. 86.

12.Соколова Л.С., Дербина А.А., Пашкова Е.Б., Пирогов А.В., Шпигун О.А. // Вестник Моск. ун-та. Сер. 2. Химия. 2015. Т. 56. № 4. C. 221.

\section{References}

1. Majstrenko V.N., Hamitov R.Z., Budnikov G.K. , Jekologicheskij monitoring supertoksikantov, M., Himija, 1996, 319 p.

2. Alemasova A.S., Lugovoj K.S. Jekologicheskaja analiticheskaja himija,. Uchebnoe posobie, Doneck: DonNU, 2010, 271 p.

3. GN 2.1.5.1315-03. Predel'no dopustimye koncentracii (PDK) himicheskih veshhestv $\mathrm{v}$ vode vodnyh obektov hozjajstvenno-pit'evogo i kul'turno-bytovogo vodopol'zovanija. Gigienicheskie normativy. M., Federal'nyj centr gigieny i jepidemiologii Rospotrebnadzora, 2003,154 c.

4. SanPin 2.1.4.1074-01. Pit'evaja voda. Gigienicheskie trebovanija $\mathrm{k}$ kachestvu vody centralizovannyh sistem pit'evogo vodosnabzhenija.
13.Пашкова Е.Б., Пирогов А.В., Юновидов Д.В., Шпигун О.А. // Вестник Моск. ун-та. Сер. 2. Химия. 2011. Т. 52. №. 1. С. 43.

14.Mel'nikov G.V., Shtykov S.N., Shtykova L.S., Goryacheva I. Yu. // Russ. Chem. Bull. Int. Ed. 2000. Vol. 49. No 9. pp. 1518.

15. Shtykov S.N, Mel'nikov G.V., Shtykova L.S. // Russ. Chem. Bull. Int. Ed. 2003. Vol. 52. No 2. pp. 398.

16.ПНД Ф 16.1:2.2:2.3:3.62-09. Количественный химический анализ почв. Методика выполнения измерений массовых долей полициклических ароматических углеводородов в почвах, донных отложениях, осадках сточных вод и отходах производства и потребления методом высокоэффективной жидкостной хроматографии. М. Федеральный центр анализа и оценки техногенного воздействия, 2009. 23 с.

17.МУК 4.1.1274-03. Измерение массовой доли бенз(а)пирена в пробах почв, грунтов, донных отложений и твердых отходов методом ВЭЖХ с использованием флуориметрического детектора. М.: Федеральный центр госсанэпиднадзора России. 2003. 29 с.

18. Canadian Soil Quality Guidelines. Carcinogenic and other polycyclic aromatic hydrocarbons (PAHs). Environmental and Human Health Effects. Scientific Criteria Document. Canadian Council of Ministers of the Environment. 2010. 215 p.

19.ГН 2.1.7.2041-06. Предельно допустимые концентрации (ПДК) химических веществ в почве Гигиенические нормативы. М. Федеральный центр гигиены и эпидемиологии Роспотребнадзора, 2006. 15 с.

Kontrol' kachestva. Gigienicheskie trebovanija $\mathrm{k}$ obespecheniju bezopasnosti sistem gorjachego vodosnabzhenija.

Sanitarnojepidemiologicheskie pravila i normativy. M.: Federal'nyj centr gigieny i jepidemiologii Rospotrebnadzora, 2002, $84 \mathrm{p}$.

5. GN 2.1.7.2041-06. Predel'no dopustimye koncentracii (PDK) himicheskih veshhestv $\mathrm{v}$ pochve. Gigienicheskie normativy. M.: Federal'nyj centr gigieny i jepidemiologii Rospotrebnadzora, 2006, $15 \mathrm{p}$.

6. GN 2.1.6.2309-07. Orientirovochnye bezopasnye urovni vozdejstvija (OBUV) zagrjaznjajushhih veshhestv v atmosfernom vozduhe naselennyh mest .Gigienicheskie normativy. M.: 
Federal'nyj centr gigieny i jepidemiologii Rospotrebnadzora, 2008, $105 \mathrm{p}$.

7. RD 52.04.186-89. Rukovodstvo po kontrolju zagrjaznenija atmosfery. M.: Goskomgidromet SSSR, 1991, 695 p.

8. Annotirovannyj spravochnik metodik vypolnenija izmerenij koncentracij zagrjaznjajushhih veshhestv $\mathrm{v}$ vybrosah promyshlennyh predprijatij, S-Pb.:NII Atmosfera, 2006, 93 p.

9. MR 146-1110. Izmerenie massovoj koncentracii benz(a)pirena $\mathrm{v}$ pit'evoj vode vol'tamperometricheskim metodom. M., Goskomsajepidnadzor, 1997.

10. Williamson K.S., Petty J.D., Huckins J.N., Lebo J.A. et al., Chemosphere, 2002, Vol. 49, pp. 703.

11.Pirogov A.V., Pashkova E.B., Popik M.V., Shpigun O.A., Razrabotka i registracija lekarstvennyh sredstv., 2013, Vol. 5, No 4, p. 86.

12.Sokolova L.S., Derbina A.A., Pashkova E.B., Pirogov A.V. et al., Vestnik Mosk. un-ta. Ser. 2. Himija, 2015, Vol. 56, No 4, pp. 221.

13.Pashkova E.B., Pirogov A.V., Junovidov D.V., Shpigun O.A., Vestnik Mosk. un-ta. Ser. 2. Himija, 2011, Vol. 52, No. 1, p. 43.

14.Mel'nikov G.V., Shtykov S.N., Shtykova L.S., Goryacheva I.Yu., Russ. Chem. Bull. Int. Ed., 2000, Vol. 49, No 9, p. 1518.

Толмачева Наталия Геннадьевна - аспирант кафедры аналитической химии химического факультета МГУ имени М.В. Ломоносова, Москва

Чжан Мончжу - аспирант кафедры аналитической химии химического факультета МГУ имени М.В. Ломоносова, Москва

Пирогов Андрей Владимирович - доктор химических наук, профессор кафедры аналитической химии химического факультета МГУ имени М.В. Ломоносова, Москва

Шпигун Олег Алексеевич - доктор химических наук, чл.-корр. РАН, профессор кафедры аналитической химии химического факультета МГУ имени М.В. Ломоносова, Москва
15. Shtykov S. N, Mel'nikov G.V., Shtykova L.S., Russ. Chem. Bull. Int. Ed., 2003, Vol. 52, No 2, p. 398.

16.PND F 16.1:2.2:2.3:3.62-09. Kolichestvennyj himicheskij analiz pochv. Metodika vypolnenija izmerenij massovyh dolej policiklicheskih aromaticheskih uglevodorodov v pochvah, donnyh otlozhenijah, osadkah stochnyh vod i othodah proizvodstva i potreblenija metodom vysokojeffektivnoj zhidkostnoj hromatografii. M.: Federal'nyj centr analiza i ocenki tehnogennogo vozdejstvija, 2009, 23 p.

17.MUK 4.1.1274-03. Izmerenie massovoj doli benz(a)pirena $\mathrm{v}$ probah pochv, gruntov, donnyh otlozhenij i tverdyh othodov metodom VJeZhH s ispol'zovaniem fluorimetricheskogo detektora. M.: Federal'nyj centr gossanjepidnadzora Rossii, 2003, 29 p.

18.Canadian Soil Quality Guidelines. Carcinogenic and other polycyclic aromatic hydrocarbons (PAHs). Environmental and Human Health Effects. Scientific Criteria Document. Canadian Council of Ministers of the Environment, 2010, $215 \mathrm{p}$.

19.GN 2.1.7.2041-06. Predel'no dopustimye koncentracii (PDK) himicheskih veshhestv $\mathrm{v}$ pochve Gigienicheskie normativy. M.: Federal'nyj centr gigieny i jepidemiologii Rospotrebnadzora, 2006, 15 p.

Tolmacheva Nataliya G. - graduate student, Chemistry Department, M.V. Lomonosov Moscow State University, Moscow, e-mail: tolmachevanatali@mail.ru

Mongjoo J.- graduate student, Chemistry Department, M.V. Lomonosov Moscow State University, Moscow

Pirogov Andrey V. - Doctor of Chemical Sciences, Professor, Chemistry Department, M.V. Lomonosov Moscow State University, Moscow

Shpigun Oleg A. - Doctor of Chemical Sciences, Professor, Chemistry Department, M.V. Lomonosov Moscow State University, Moscow. 